\section{Immaginare Corviale, proyección y pantalla}

Immaginare Corvialle, projection and screen

\author{
Camila Medina
}

Palabras Clave Immaginare Corviale
Resumen Entre los años 2004 y 2005, Stalker/Osservatorio Nomade desarrolló el proyecto Immaginare Corviale. Su objetivo era transformar la imagen estigmatizada de Corviale: un edificio moderno de casi un kilómetro de largo ubicado en la periferia de Roma. Las operaciones de Immaginare Corviale alejadas de la construcción y la remodelación - fueron de índole artístico, académico y de comunicación. Usando los conceptos de telón y pantalla definidos por W.J. T. Mitchell, propongo que el proyecto actúa como telón al proyectar una nueva imagen del edificio y sus habitantes; y como pantalla, al conectar realidades distintas y actuar como medio de comunicación.

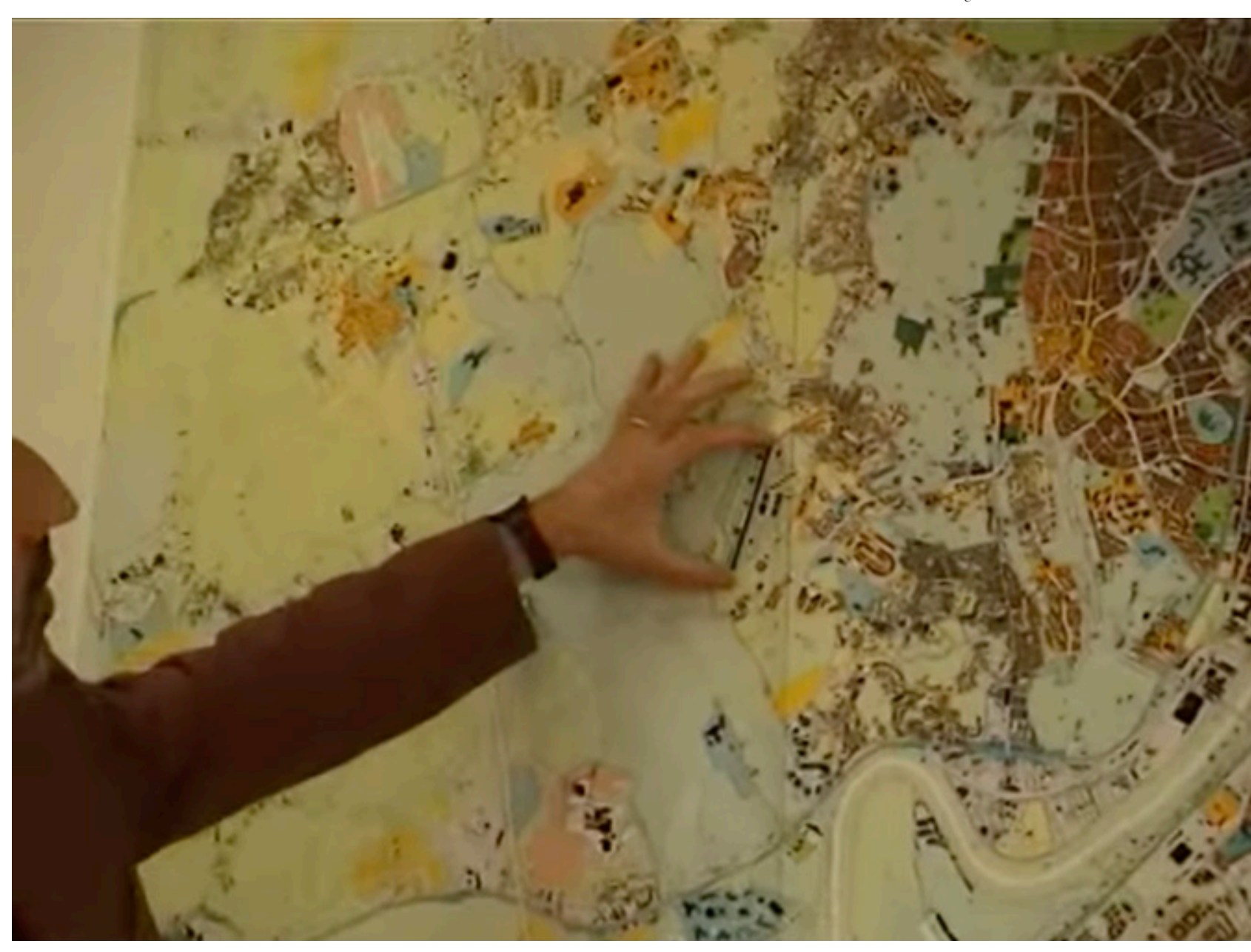


"Un kilómetro de largo;" muestra el director del Laboratorio Territorial sobre el plano. Separando sus dedos diez centímetros, indica la posición y medida del edificio Corviale en la periferia de Roma. Revela también su escala comparando esa distancia con otro sector de la ciudad. "Es un monumento," dice, "Es un monumento a la utopía." ${ }^{1}$ En el edificio Corviale reside —además de al menos 4500 personas - la utopía moderna, el sueño de resolver la complejidad de la vida doméstica y social a través de la organización espacial de las actividades en un edificio de hormigón. Es un volumen claro, estéticamente ambicioso, una línea con espesor que se levanta del suelo para dejar espacio a un paisaje también utópico: una naturaleza bucólico-pastoril, común y "pública". De perfecto Estilo Internacional -le diríamos a Mario Fiorentino, el arquitecto.

Pero en este texto, no voy a hablar de Corviale, porque no interesa aquí el edificio en sí mismo sino un proyecto para la transformación de su imagen: Immaginare Corviale [IC]. Éste, fue desarrollado e implementado por Stalker/Osservatorio Nomade [ON], bajo el encargo de la Fundación Olivetti, entre los años 2004 y 2005 ¿Quiénes viven en Corviale y qué significa para ellos residir en la periferia? El colectivo romano, que venía desarrollando proyectos enfocados en "sitios urbanos ocultos" e "historias reprimidas," se dispuso con IC a superar la percepción marginal y decadente del edificio suburbano (que lo perseguía desde la década de los '80). ${ }^{3}$ Más específicamente - y a diferencia de una intervención arquitectónico-constructiva-las acciones realizadas consistieron en una serie de operaciones participativas que incluían intervenciones artísticas en terreno, talleres universitarios y un programa de televisión barrial. "Es un proyecto que encuentra en la administración un idioma [...] y entiende al habitante de Corviale como territorio de la acción" explica Lorenzo Romito - de Observatorio Nomade - para el video realizado por Michela Franzoso, hacia el 2005. ${ }^{4}$

Si el objetivo de IC era cambiar la imagen de Corviale, podríamos decir que el proyecto funcionó como un telón para proyectar una nueva identidad social a servicio de sus habitantes. Bajo esta premisa, me interesó la relación entre este telón y la creación de una televisión barrial. Corviale Network [CN] fue un experimento de televisión que pretendía crear ".. una imagen 'inmediata' contrapuesta a la imagen mediática establecida [por la prensa escrita]".5 El equipo editorial de este medio de comunicación no sólo estaba compuesto por miembros de $\mathrm{ON}$, sino también por residentes de Corviale. Las audiciones - para seleccionar de entre los vecinos a los hostsse filmaban en los ascensores, espacio de encuentro icónico de la vivienda en altura. Algunas de estas tomas fueron usadas en el video de Franzoso. En él, se muestra a los participantes en una secuencia de grabaciones que transicionan en swipe vertical: "Iride, per Corviale Network." El edificio ya tiene voz, agencia y rostro. ${ }^{6}$

Usando los conceptos del historiador del arte W. J. T. Mitchell, si Immaginare Corviale es telón, "una superficie reflectante sobre la que se pueden proyectar imágenes en sombra," Corviale Network es pantalla, "un medio de transmisión, en el que las imágenes nos llegan desde detrás de la superficie y, de hecho, desde una fuente muy alejada de la escena del espectador." El primero corresponde a un EN y el segundo a un A TRAVÉS; el primero es sustento, es decir, un sistema de organización de estrategias y un medio de visibilización; mientras que el segundo es mediación, es decir, conexión entre situaciones e imaginarios distantes; un medio de comunicación ?

$\mathrm{CN}$ no cambia las estructuras fundamentales de la arquitectura - ni mucho menos se basa en operaciones de remodelación - sino más bien actúa como un mediador de relaciones sociales. Hace a los habitantes producir escenas de contenido doméstico, las edita y las transmite, para ser vista luego por los mismos habitantes. En él se representa una comunidad y con ello, al mismo tiempo, se crea. Si lo simbólico es intrínseco a la arquitectura monumental de Corviale, ¿̇porqué no podría un proyecto mediático ser capaz de cambiar un edificio desde su significado? IC, solo como telón, dejaría algo detrás sin iluminar. Su estrategia de comunicación barrial - la pantalla transmisora - atenúa la sombra de los vicios de la arquitectura moderna y de los suburbios de emergencia. Consecuentemente, propongo entender IC como un proyecto de arquitectura de medios, que construye más que una imagen proyectada, es un sistema de reconocimiento y comunicación; para permitir así, la evolución de esa representación. figura 2 2

"Immaginare Corviale 2005- Stalker
Osservatorio Nomade" $7 \mathrm{~m} 56 \mathrm{~s}$

Michela franzoso
(Imagen cortesia de Stalker)

figura 3

Capturas del vídeo
"Immaginare Corviale 2005- Stalker
Oscervatorio Nomade" $11 \mathrm{~m} 2 \mathrm{~s}$ Michala Franzoso
(Imagen cortesia de Stalker)

figura 4
Capturas del víde "Immaginare Corviale 2005 - Stalker $12.16 \mathrm{~s}$ Michela Franzoso
(Imagen cortesia de Stalker)
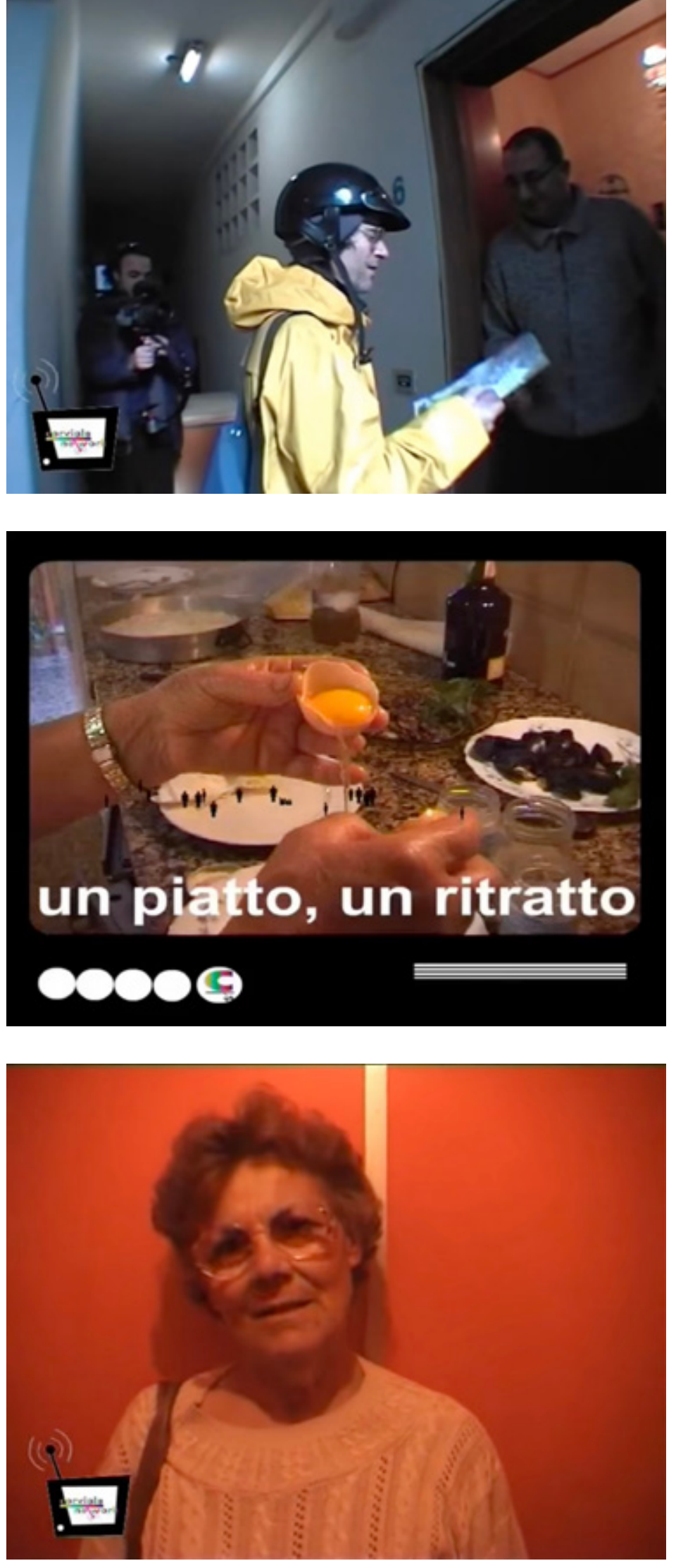
4.

- Tor

5.

Texto original: "un esperimento concreto di televisione di quartiere il cui obiettivo era liberare Corviale dellla condanna che ne ha fatto il simblolo deli iorrorid della perifertia, dando Gennari Santori, y Bartolomeo Pientromarchi. Osservatoroio nomade, immaginare Corviale [pratiche ed estetiche per la citrà contemporanea]. (Milano: B. Mondadori, 2006)

6.

7.

Cita original: "The 'on/through" distinction is familiar to us in the difference between the
cinematic and televisual screen. The film screen is a reflective surface on which shadow images can be projected; the latter is a transmission medium, in which the images come to us from
behind the suffice and indeed from s source far removed from the sees of En WJ.T. Mitchell. "Screening nature (and the nature of the screen)." New Review of Film

\section{Camila Medina}

Pontificia Universidad Católica de Chile. Arquitecta y Magíster en
Arquitectura del Paisaje, Pontificia Universidad Católica de Chile (2014), CoFundadora de LOFscapes (2015) y, actualmente, estudiante de doctorado en
LUS, ETH, Zürich. Se ha desenvuelto como docente en diversas universidades U. en Chile, ejerciendo como editora gental del libro de LOFscapes: Paisaje no es

\section{Bibliografía}

Careri, Francesco. "Modello Corviale, Azioni e Programmi tra Arti, Architettura e Urbanistica”, Pop Housing, a Cura di Fabio Ciaravella, editado por Favio Ciaravella, 58-71. Siracusa, Letteraventidue Edizioni, 2021

Düblin, Patrick "Architecture of Direct Action: Stalker/ Osservatorio Nomade," PhD. Abstract (en proceso), ETH Zürich.Visto en: https://girot.arch.ethz.ch/research/stalkerosservatorio-nomade

Franzoso, Michela. "Immaginare Corviale 2005 - Stalker Osservatorio Nomade", Stalker, 2 de febrero de 2016 (2005), video, $29 \mathrm{~m} 51 \mathrm{~s}$, https://www.youtube.com/watch?v=rna UYMnRZk\&t=246s

UYMnRZk\&t=246s

Flaminia, y Bartolomeo Pietromarchi. Osservatorio nomade, immaginare Corviale: [pratiche ed estetiche per la città contemporanea]. Milano, B. Mondadori, 2006.

Mitchell, W.J.T. "Screening nature (and the nature of the screen)." New Review of Film and Television Studies 13:3 (2015):231-246

"Immaginare Corviale. Osservatorio Nomade" en Roulotte

Magazine. Visto en: https://roulottemagazine.com/ es/2011/04/immaginare-corviale-osservatorio-nomade/ 